\title{
Association between polymorphisms of genes involved in the Renin-Angiotensin-Aldosterone System and the adaptive morphological and functional responses to essential hypertension
}

\author{
OANA MOCAN $^{1}$, DAN RĂDULESCU ${ }^{1}$, ELENA BUZDUGAN $^{1}$, ANGELA COZMA $^{2}$, \\ DANIEL CORNELIU LEUCUTA ${ }^{3}$, SIDONIA ALINA BOGDAN ${ }^{4}$ and LUCIA MARIA PROCOPCIUC ${ }^{5}$
}

${ }^{1}$ Department of Internal Medicine, 5th Medical Clinic; ${ }^{2}$ Department of Internal Medicine, 4th Medical Clinic, 'Iuliu Haţieganu’ University of Medicine and Pharmacy, 400012 Cluj-Napoca;

${ }^{3}$ Department of Medical Informatics and Biostatistics, 'Iuliu Hațieganu' University of Medicine and Pharmacy, 400349 Cluj-Napoca; ${ }^{4}$ Department of Surgery, Faculty of Veterinary Medicine, University of Agricultural Science and Veterinary Medicine, 400372 Cluj-Napoca; ${ }^{5}$ Department of Medical Biochemistry, 'Iuliu Hațieganu' University of Medicine and Pharmacy, 400349 Cluj-Napoca, Romania

Received May 11, 2021; Accepted July 13, 2021

DOI: $10.3892 / b r .2021 .1456$

\begin{abstract}
Hypertensive cardiac remodeling is illustrated by increased left ventricular (LV) mass index values and/or relative wall thickness (RWT) values $>0.42$, and functionally by isolated alteration of LV diastole (abnormal relaxation). The aim of the present study was to establish differentiated models of anatomical and functional adaptation to essential hypertension (EHT), in relation to the genetic variants of genes involved in the Renin-Angiotensin-Aldosterone System (RAAS). The M235T-AGT, I/D-ACE, A1166C-R1AngII, A3123C-R2AngII and G83A-REN genotypes were determined using PCR-Restriction Fragment Length Polymorphism in 139 hypertensive subjects. The relationship between the studied RAAS gene polymorphisms with morphological and functional cardiac remodeling was assessed by multiple logistic regression analysis. Patients carrying the $C / C, A / C$ genotypes (A3123C-R2AngII polymorphism) had a 2.72 -fold $(\mathrm{P}=0.033)$ increased risk of exhibiting an RWT value $<0.42$; in the multivariate model the risk was 4.02 -fold higher $(\mathrm{P}=0.008)$. Analysis of LV diastolic dysfunction (LVDD) revealed that hypertensive patients carrying the $T / T, M / T$ genotypes (M235T-AGT polymorphism) had a 2.24 -fold $(\mathrm{P}=0.037)$ increased risk of developing LVDD and a 2.42-fold increased risk $(\mathrm{P}=0.039)$ after adjustment for confounders. Similarly, carriers of the $G / G, A / G$ genotypes (G83A-REN)
\end{abstract}

Correspondence to: Dr Elena Buzdugan, Department of Internal Medicine, 5th Medical Clinic, 'Iuliu Hațieganu' University of Medicine and Pharmacy, 8 Babeş Street, 400012 Cluj-Napoca, Romania

E-mail: cristina.buzdugan@umfcluj.ro

Key words: essential hypertension, cardiac remodeling, left ventricular hypertrophy, diastolic dysfunction, genetic polymorphisms had a 2.32-fold $(\mathrm{P}=0.021)$ increased risk of developing LVDD, and this remained an independent risk factor based on the multivariate model $(\mathrm{P}=0.033)$. The results of the present study showed that no particular gene was associated with increased LV mass, but the A3123C-R2AngII polymorphism was associated with a non-concentric type of cardiac response in hypertensive patients. Conversely, the M235T-AGT and G83A-REN polymorphisms were found to be statistically significantly associated with LVDD when assessing abnormal relaxation.

\section{Introduction}

Essential hypertension (EHT) is the form of hypertension that by definition has no identifiable secondary cause and may be considered, according to the risk of ischemic cardiac and cerebrovascular events in disease staging, when organ damage, including left ventricular hypertrophy (LVH), is present (1-3). The type of cardiac remodeling is influenced by the evolution of EHT, associated pathologies [diabetes mellitus (DM) or chronic kidney disease (CKD) in the dialysis stage], phenotype (age, obesity and sex) and genetic factors (4-7).

Heart failure (HF) with a preserved ejection fraction is associated with left ventricular diastolic dysfunction (LVDD) (2). LVDD is defined as increased resistance to LV filling (2). LVDD is influenced by humoral and hemodynamic factors, and may represent a stage in the evolution of hypertension (2). The causes can include mechanical obstruction of filling (myocardial fibrosis), impaired ventricular relaxation and compliance in LVH, or ischemic heart disease (IHD) $(8,9)$.

The Renin-Angiotensin-Aldosterone System (RAAS) is involved in the pathophysiological process of EHT (10). The RAAS consists of angiotensinogen (AGT), angiotensin I (AngI), angiotensin II (AngII), AngI to AngII converting enzyme (ACE), AngII type 1 receptor (R1 AngII), AngII type 2 receptor (R2 AngII) and renin (REN) (11). RAAS exerts its effects through neurohumoral mechanisms to regulate blood 
pressure (BP) in the pathophysiological process of cardiac remodeling $(4,12)$, and RAAS components have been implicated in functional LV remodeling in the pathophysiological mechanism of LVDD $(13,14)$.

AGT is involved in the pathogenesis of EHT, is a growth factor for myocytes and it induces cardiac hypertrophy (11). The M235T genetic variant (chr 1q42-q43) is a point substitution in which methionine is replaced by threonine at position 235 (15). Hypertensive patients carrying the M235T-AGT genotype have an increased risk of LVH and IHD, as they exhibit increased plasma AGT levels $(12,16)$. The M235T-AGT genotype is associated with increased AGT levels, TThomozygotes are at a high risk for LVD and IHD. Male and female athletes carrying the TT-AGT genotype exhibit LVH as an adaptive response to exercise (16).

ACE plays a role in converting AngI to AngII $(12,17)$. ACE and AngII are involved in the pathophysiological process of $\mathrm{LVH}$, independently of hemodynamic factors (6). Insertion/deletion (I/D) at position 16 of the ACE gene (chr 17q23.3) influences the activity of ACE and AngII. ACE accelerates cardiac fibrosis progression and the increase in LV mass, which is why hypertensive homozygous carriers of the $D D$ allele have an increased risk for LVH and IHD $(4,17,18)$. This aspect of the increased risk of LVH associated with the $D D$ genotype differs depending on the geographical area and race, with Caucasians being at highest risk (4). I/D-ACE polymorphisms are associated with the increase in $\mathrm{LV}$ mass in hypertensive and normotensive patients $(2,6,17,19)$. Normotensive athletes carrying the $D D$ genotype have a greater increase in heart muscle mass compared with athletes carrying the $I / I$ genotype (19). I/D-ACE polymorphisms are associated with the increase in LV mass in hypertensive and normotensive subjects, and the $D$ allele is most frequently associated with $\operatorname{LVH}(2,6,17,19)$.

R1 AngII and R2 AngII are part of the G-protein coupled receptor family (20). After binding R1, Ang II activates its role in stimulating the release of aldosterone, regulating vasoconstriction, cell proliferation and the increase in mitosis of smooth and striated muscle fibers $(6,20,21)$. The A1166C-R1AngII genetic variant is a point mutation in the R1 AngII gene (chr 3q21-q25) in which the adenine nucleotide at position 1,166 of the gene is replaced by cytosine. It is associated with the synthesis of type I collagen located in the myocardium, which explains its role in the pathogenesis of $\mathrm{LVH}$ and $\operatorname{IHD}(6,17,22)$.

The A3123C-R2AngII genetic variant is a point mutation in the R2 AngII gene in which the adenine nucleotide is replaced by cytosine at position 3,123 of the gene (23). R2 AngII expression can influence the pathophysiological process of EHT and cardiac remodeling (24).

REN is an aspartate protease, which is involved in the cleavage of the AGT precursor to Ang I, and activates the RAAS cascade (25). REN activity is associated with the BP response to salt consumption and antihypertensive treatment (26). The G83A-REN genetic variant is a point mutation in the which guanine is replaced by adenine at position 83 of the renin gene (chr 1q32). It is associated with an increase in REN activity and EHT pathophysiology, as well as ischemic and hemorrhagic cerebral events (25).

The association of at least 2 genes increases the risk of cardiovascular complications, such as LVH, IHD and heart failure, in hypertensive patients $(4,27,28)$.
Although there are several factors that contribute to hypertensive remodeling, the aim of the present study was to identify the distribution of various RAAS genetic polymorphisms in the patterns of cardiac structural and functional adaptation to EHT.

\section{Materials and methods}

Study design and setting. The present study was a prospective cross-section study performed on patients with EHT, who were being followed up, were under treatment or were newly diagnosed, from three medical centers in Cluj-Napoca, Romania June 2015 and December 2017. The patients were selected on the occasion of ambulatory examinations or hospitalization to internal medicine or cardiology services. The study group consisted of 139 subjects, 71 females and 68 males, with a median age (IQR) of 61 (49.5-67) and an age range of 23-86 years.

Written informed consent was obtained from all participants, prior to their inclusion in the study. The Ethics Committee of the 'Iuliu Hatieganu' University of Medicine and Pharmacy approved the study (approval no. 333/2.06.2015).

Study group. To ensure homogeneity of the studied groups, patients with secondary hypertension, left ventricular ejection fraction (LVEF) $<50 \%$, with HF New York Heart Association functional class III and IV, with unstable coronary disease, CKD with a glomerular filtration rate $<30 \mathrm{ml} / \mathrm{min} / 1.72 \mathrm{~m}^{2}$ or in the dialysis stage were all excluded.

At 5 min prior to the beginning of the examination, systolic $\mathrm{BP}$ (SBP) and diastolic BP (DBP) were measured as the patient was sitting or lying down, with a manual BP monitor; three successive measurements were taken 2-5 min apart. Newly diagnosed EHT was defined according to the European Society of Hypertension Guidelines as values $\geq 140 / 90 \mathrm{mmHg}$ (1).

Detailed history was taken for each patient including their age, sex, weight $(\mathrm{kg})$ and height $(\mathrm{cm})$. The body mass index (BMI) was also calculated based on the formula: BMI=weight (kg)/[height (m) $]^{2}$.

Cardiac ultrasonography. All patients included in the present study underwent cardiac ultrasound in $\mathrm{M}$ and 2D mode, using a Samsung H60 (Samsung Medison) or Aloka Alpha 7 (Aloka Ltd.) ultrasound systems, with transducers at frequencies ranging between 2-4 Mhz.

The examinations were performed in left lateral decubitus. The end-diastolic interventricular septum (IVSd), the end-diastolic LV posterior wall (PWd), as well as the LV end-systolic diameter (LVESD) and LV end-diastolic diameter (LVEDD) were measured in parasternal long axis incidence, perpendicular to the LV long axis, and measured at the level of the mitral valve leaflet tips, with the values being expressed in $\mathrm{mm}$.

The LV mass (LVM), expressed in grams, was calculated based on the Devereaux formula: LVM $(\mathrm{g})=0.8[1.04$ [([LVEDD+ IVSd+PWd $]^{3}-$ LVEDD $\left.\left.\left.^{3}\right)\right]\right]+0.6$. The LVM index (LVMI) was calculated as the ratio of the LVM to the body surface area $\left(\mathrm{g} / \mathrm{m}^{2}\right)$.

LVH was defined based on the following criteria: LVMI $>131 \mathrm{~g} / \mathrm{m}^{2}$ in men, and $>108 \mathrm{~g} / \mathrm{m}^{2}$ in women. To differentiate concentric from eccentric $\mathrm{LVH}$, the relative wall thickness 
(RWT) was also calculated according to the formula: RWT $=2 \mathrm{x}$ PWD/LVEDD.

According to Ganau's criteria, 4 types of cardiac remodeling were considered: i) normal geometry, with the absence of LVH and with an RWT value $<0.42$; ii) concentric hypertrophy, with the presence of LVH and an RWT value $\geq 0.42$; iii) eccentric hypertrophy, with the presence of LVH and an RWT value $<0.42$; and iv) concentric remodeling, with the absence of LVH and an RWT value $\geq 0.42$ (5).

LVEF was calculated using LVESD and LVEDD values based on the Teicholz formula using an online tool (e-echocardiography.com) (29). To assess LV diastolic function, pulsed Doppler was used. The LV diastolic filling mitral flow was measured in the apical incidence. The peak of early passive filling velocity ( $\mathrm{E}$ wave) and late active filling velocity corresponding to atrial contraction (A wave) was recorded and the E/A ratio was calculated. Peak E-wave velocity $(\mathrm{cm} / \mathrm{sec})$ and peak A-wave velocity $(\mathrm{cm} / \mathrm{sec})$ were measured in the apical four-chamber view, with color flow imaging for optimal alignment of power Doppler; blood flow and power Doppler sample volume was 1-3 mm axial size, between the mitral leaflet tips. Peak E-wave velocity $(\mathrm{cm} / \mathrm{sec})$ was calculated in peak modal velocity in early diastole (after ECG T wave) at the leading edge of spectral waveform. Peak A-wave velocity $(\mathrm{cm} / \mathrm{sec})$ was calculated in peak modal velocity in late diastole (after the ECG P wave) at the leading edge of the spectral waveform. Evaluations of 5 different diastoles were performed and their mean was calculated. The isolated LVDD is expressed by E/A $<1$, and was defined as abnormal relaxation.

Genetic determinations; identification of M235T-AGT, I/D-ACE, A1166C-R1AngII, C3123A-R2AngII and G83A-REN genotypes. For genetic determination, $5 \mathrm{ml}$ venous blood was collected in vacutainers with EDTA. Genomic DNA was isolated from peripheral leukocytes using a Quick-DNA-Miniprep kit (Zymo Research).

To identify M235T-AGT, I/D-ACE, A1166C-R1AngII, A3123C-R2AngII and G83A-REN genotypes, the methods described by Procopciuc et al (15), as well as specific primers (Table I) were used (Kaneka Eurogentec S.A.) (15). Amplification was performed in an iCycler (Bio-Rad Laboratories, Inc.) in a $25 \mu \mathrm{l}$ reaction mixture consisting of 20 ng DNA, $0.2 \mu \mathrm{M}$ primers, $2.0 \mathrm{mM} \mathrm{MgCl} 2,200 \mu \mathrm{M}$ dNTPs and $2 \mathrm{U}$ Taq polymerase in a specific buffer: $10 \mathrm{X}$ Taq buffer with $\left(\mathrm{NH}_{4}\right)_{2} \mathrm{SO}_{4}\left(750 \mathrm{mM}\right.$ tris- $\mathrm{HCl}\left(\mathrm{pH} 8.8\right.$ at $\left.25^{\circ} \mathrm{C}\right), 200 \mathrm{mM}$ $\left(\mathrm{NH}_{4}\right)_{2} \mathrm{SO}_{4}, 0.1 \%$ (v/v) Tween-20).

For M235T-AGT, I/D-ACE, A1166C-R1AngII, A3123CR2AngII, $G 83 A$-REN genetic variants, the amplified fragments were subjected to enzymatic digestion with specific restriction enzymes for $3 \mathrm{~h}$.

The amplified and enzymatic digestion fragments were visualized by UV light through migration in 2 and $3 \%$ agarose gels, respectively, stained with $10 \mathrm{mg} / \mathrm{ml}$ ethidium bromide.

All PCR-Restriction Fragment Length Polymorphism reagents were obtained from Fermentas (Thermo Fischer Scientific Inc.) and Jena Bioscience (Analytik Jena AG), except for the primers, which were from Eurogentec (Kaneka Eurogentec S.A.).

The amplification and enzymatic digestion conditions are presented in Table I, and the fragments obtained by enzymatic digestion for all the studied RAAS genetic variants are presented in Fig. 1.

Statistical analysis. Categorical variables were reported as absolute and relative frequencies. The associations between categorical variables were tested using a $\chi^{2}$ test or a Fisher's exact test (in cases of lower than expected frequencies). The associations between binary data were assessed with odds ratios and $95 \%$ confidence intervals. An exact test was used to check the Hardy-Weinberg equilibrium. Data that were normally distributed are presented as the mean \pm standard deviations, and compared using an unpaired Student's t-test or one way ANOVA (30). Skewed data are presented as the medians and interquartile ranges, and a Wilcoxon rank-sum test or a Kruskal-Wallis test were used to compare the different groups.

To assess the associations between polymorphisms with abnormal relaxation or RWT values $>0.42$, first, univariate logistic regression analyses were used. Multivariate logistic regression models where next used, adjusting each polymorphism for age (years), BMI $\left(\mathrm{kg} / \mathrm{m}^{2}\right)$, SBP $(\mathrm{mmHg})$ and DBP $(\mathrm{mmHg})$. For all multivariate logistic regression models, multicollinearity was assessed for using the variance inflation factor. The linearity of log odds in cases of continuous covariates were examined, using splines terms in a generalized binomial additive model, and if the assumption did not hold the continuous covariate was replaced, in the logistic regression model, with a binary transformation using the median as the cutoff. All logistic regression models are presented using odds ratios, with $95 \%$ confidence intervals and $\mathrm{P}$-values.

For all statistical tests, a two-tailed P-value $<0.05$ was considered to indicate a statistically significant difference. All analyses were computed using R environment for statistical computing and graphics (R Foundation for Statistical Computing, Vienna, Austria), version 3.6.2 (31). The Hardy-Weinberg equilibrium test was computed using the package SNPassoc 1.9-2 (32).

\section{Results}

Patients' characteristics according to LVH status. The characteristics of the subjects in the study cohort are presented in Tables II and III. The most frequent LVH was concentric remodeling, 59 patients $(42.45 \%)$, followed by concentric hypertrophy, 48 patients $(34.53 \%)$ and eccentric hypertrophy, 8 patients $(5.75 \%)$.

The mean age was statistically significant $(\mathrm{P}<0.002)$, a decade higher in subjects with LVH compared to those with normal geometry. The weight status differed significantly amongst groups $(\mathrm{P}<0.004)$, with individuals more likely to be overweight in the concentric hypertrophy group (54.17\%), followed by the eccentric hypertrophy group (37.5\%). Obesity was more common in the eccentric hypertrophy group $(62.5 \%)$, followed by the concentric remodeling group (55.93\%). The SBP differed significantly amongst groups $(\mathrm{P}<0.001)$, the highest values were observed in the concentric hypertrophy group compared to the other LV geometry groups.

Abnormal relaxation was statistically significantly associated with LV geometries $(\mathrm{P}<0.009)$, being more frequent in the eccentric hypertrophy group (75\%), followed by 


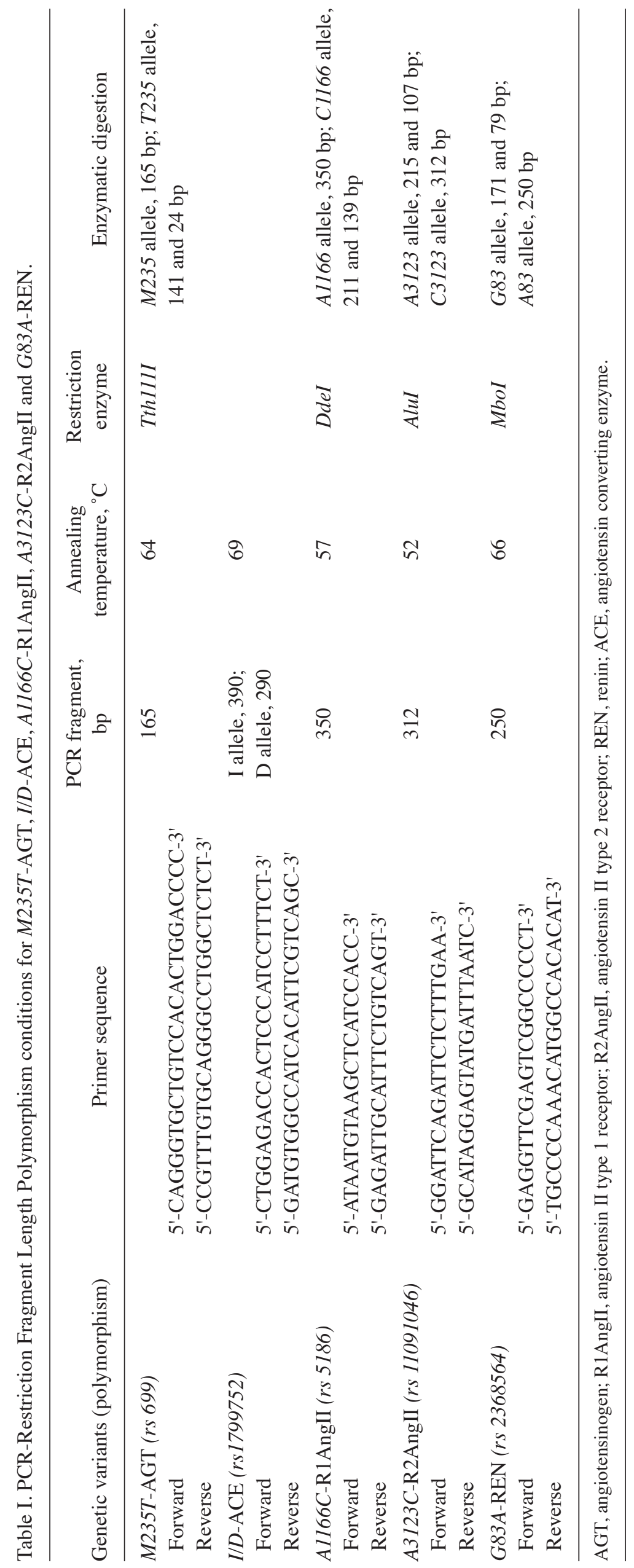


A
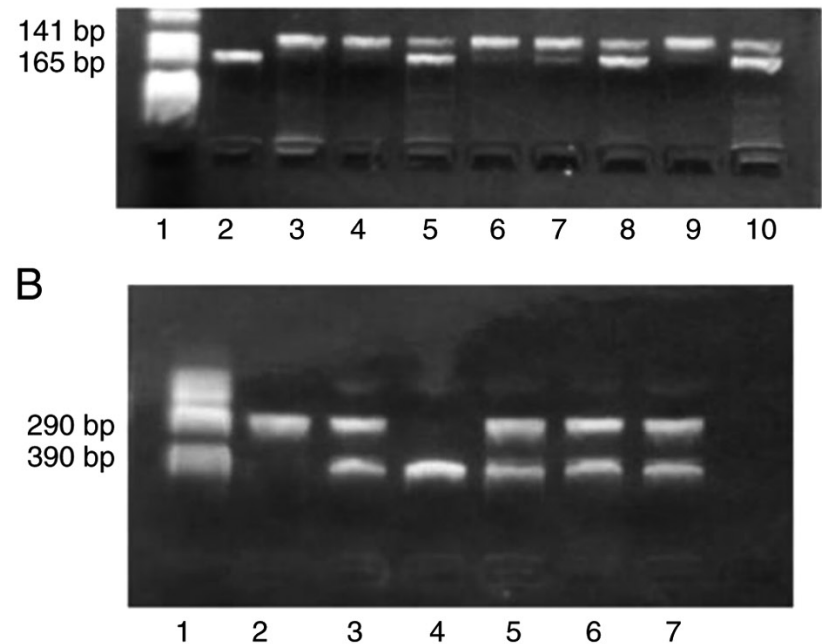

C

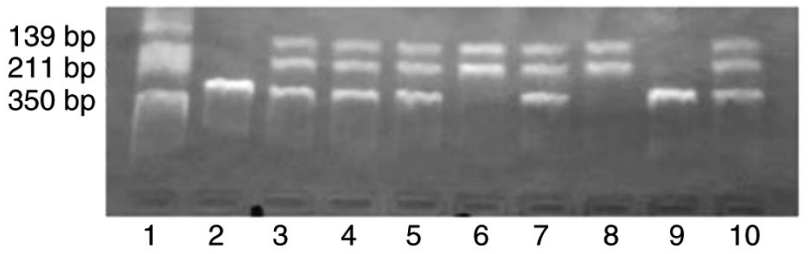

D
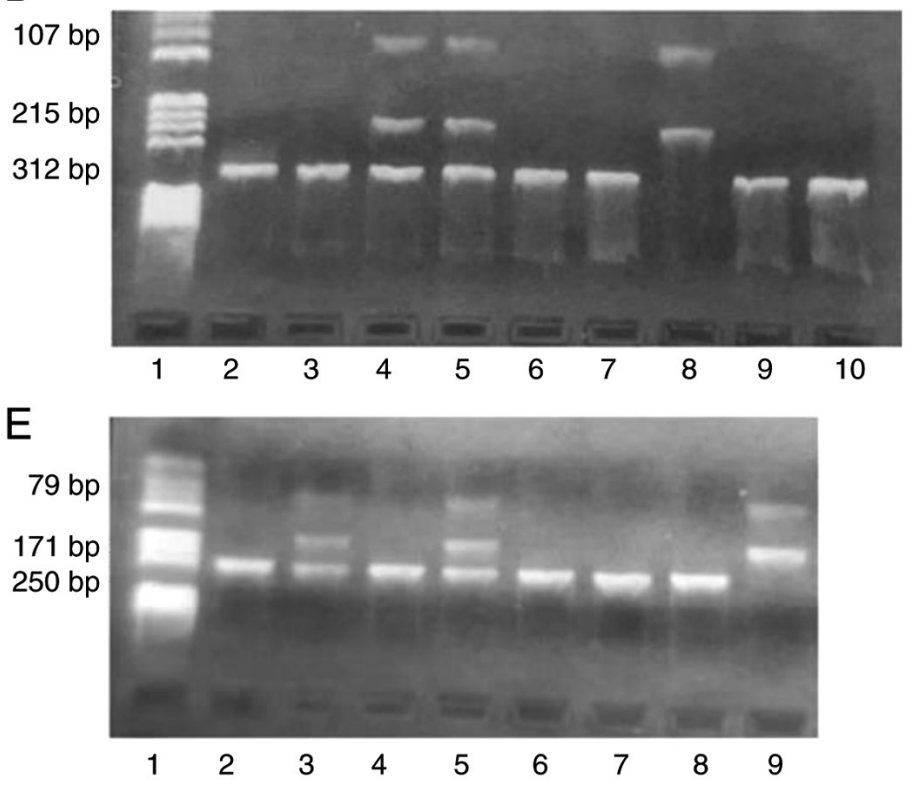

Figure 1. PCR amplification and enzymatic digestion for identification of RAAS polymorphisms. (A) M235T-AGT: lane 1-pBRHaeIII Digest DNA molecular marker; lane 2-M/M homozygous genotype, 165 bp fragment; lanes 3, 4, 6 and 9-T/T homozygous genotype, 141 bp fragment; lanes 5, 7, 8 and 10-M/T heterozygous genotype, 165 and 141 bp fragments. (B) I/D-ACE: lane 1-pBRHaeIII Digest DNA molecular marker; lane 2-D/D homozygous genotype, 290 bp fragment; lanes 3, 5, 6 and 7-I/D heterozygous genotype, 390 and 290 bp fragments; lane 4-I/I homozygous genotype, 390 bp fragment. (C) A1166C-R1AngII: lane 1-pBRHaeIII Digest DNA molecular marker; lanes 2 and 9-A/A homozygous genotype, 350 bp fragment; lanes 3, 4, 5, 7 and 10-A/C heterozygous genotype, 350, 211 and 139 bp fragments; lanes 6 and 8-C/C homozygous genotype, 211 and 139 bp fragments. (D) A3123C-R2AngII: lane 1-pBRHaeIII Digest DNA molecular marker; lanes 2,3, 6, 7,9 and 10-C/C homozygous genotype, 312 bp fragment; lanes 4 and 5-C/A heterozygous genotype, 312, 215 and 107 bp fragments; lane 8-A/A homozygous genotype, 215 and 107 bp fragments. (E) G83A-REN: lane 1-pBRHaeIII Digest DNA molecular marker; lanes 2 , 4, 6, 7 and 8-A/A homozygous genotype, 250 bp fragment; lanes 3 and 5-A/G heterozygous genotype, 250 , 171 and 79 bp fragments; lane 9-G/G homozygous genotype, 171 and 79 bp fragments.

concentric hypertrophy $(72.92 \%)$ and concentric remodeling (64.41\%) (Table II).

Patients' characteristics according to diastolic function (abnormal relaxation). LVDD as expressed by abnormal relaxation was present in 87 (62.58\%) subjects. Compared to the group with absence of abnormal relaxation, the mean age, SBP and DBP were higher in the group of hypertensive patients with LVDD. The results obtained showed a statistically significantly higher number of hypertensive patients with LVDD aged $>60$ years $(\mathrm{P}<0.007)$.

There were more overweight subjects, 32 (36.78\%) and obese subjects, $(54.02 \%)$, in the group with LVDD. The patients with abnormal relaxation had abnormal 47 geometries, namely concentric hypertrophy, 35 patients (40.23\%), eccentric hypertrophy, 6 patients $(6.9 \%)$, and concentric remodeling, 38 patients $(43.68 \%)$, compared with patients with absence of abnormal relaxation. The differences between the two groups were only statistically significant different with regard to age $(\mathrm{P}<0.001)$ and the presence of LVH $(\mathrm{P}<0.009)$.

Hypertensive patients with LVDD had a median of RWT value $(\mathrm{P}<0.001)$, LVM $(\mathrm{g})(\mathrm{P}<0.028)$, and LVMI $\left(\mathrm{g} / \mathrm{m}^{2}\right)$ $(\mathrm{P}<0.008)$ in a statistically significantly higher proportion than hypertensive patients without LVDD. Accordingly, the frequency of RWT $<0.42(\mathrm{P}<0.003)$ and of pathological LVMI $\left(\mathrm{g} / \mathrm{m}^{2}\right)(\mathrm{P}<0.033)$ was statistically significantly lower in the group with LVDD (Table III).

Associations between the RAAS polymorphisms and abnormal relaxation. There were statistically significant associations between LVDD and genetic variants M235T-AGT $(\mathrm{P}<0.035)$, A1166C-R1AngII $(\mathrm{P}<0.046)$, G83A-REN $(\mathrm{P}<0.02)$ in the univariate logistic regression analysis. The association was maintained even after adjustment for confounders (age, sex, BMI, SBP and DBP), for patients carrying the $M / T, T / T$ genotypes (M235T-AGT polymorphism) $(\mathrm{P}<0.039)$ and for patients carrying $G / G-A / G$ genotypes ( $G 83 A-\mathrm{REN}$ polymorphism) $(\mathrm{P}<0.033)$, but not for patients carrying $C / C, A / C$ genotypes (A1166C-R1AngII polymorphism) $(\mathrm{P}<0.105)$.

Compared to the negative carriers, the chances of hypertensive patients exhibiting LVDD was $2.22 \mathrm{x}$ higher in carriers of the $T / T, M / T$ genotypes without adjustment, and $2.42 \mathrm{x}$ higher after adjustment for confounders. The chances of exhibiting LVDD was 2.32 x higher in carriers of the $G / G-A / G$ genotypes compared to the $A / A$ genotype without adjustment, and 2.39x higher after adjustment for confounders.

There was no statistically significant associations of I/D-ACE $(\mathrm{P}=0.977)$ and A3123C-R2AngII $(\mathrm{P}=0.202)$ gene variants with abnormal relaxation (Table IV). 
Table II. Characteristics of the patients with essential hypertension with regard to the left ventricular pathophysiology.

\begin{tabular}{|c|c|c|c|c|c|}
\hline \multirow[b]{2}{*}{ Characteristic } & \multicolumn{4}{|c|}{ Left ventricular geometry } & \multirow[b]{2}{*}{ P-value } \\
\hline & $\begin{array}{c}\text { Normal } \\
\text { geometry, } \\
n=24\end{array}$ & $\begin{array}{c}\text { Concentric } \\
\text { hypertrophy, } \\
n=48\end{array}$ & $\begin{array}{c}\text { Eccentric } \\
\text { hypertrophy, } \\
n=8\end{array}$ & $\begin{array}{l}\text { Concentric } \\
\text { remodeling, } \\
n=59\end{array}$ & \\
\hline $\begin{array}{l}\text { Age, years, mean } \\
\text { (standard deviation) }\end{array}$ & $49.25(13.48)$ & $59.9(10.87)$ & $61.5(13.33)$ & $59.46(11.97)$ & $0.002^{\mathrm{a}}$ \\
\hline \multicolumn{6}{|l|}{ Sex, n $(\%)$} \\
\hline Female & $9(37.5)$ & $27(56.25)$ & $6(75)$ & $29(49.15)$ & 0.253 \\
\hline Male & $15(62.5)$ & $21(43.75)$ & $2(25)$ & $30(50.85)$ & \\
\hline Weight status, n (\%) & & & & & $0.004^{\mathrm{a}}$ \\
\hline Healthy weight & $4(16.67)$ & $2(4.17)$ & $0(0)$ & $13(22.03)$ & \\
\hline Overweight & 7 (29.17) & $26(54.17)$ & $3(37.5)$ & $13(22.03)$ & \\
\hline Obesity & $13(54.17)$ & $20(41.67)$ & $5(62.5)$ & $33(55.93)$ & \\
\hline $\begin{array}{l}\text { Systolic blood pressure, } \\
\mathrm{mmHg} \text {, median (IQR) }\end{array}$ & $160(150-170)$ & $170(160-180)$ & $160(148.75-180)$ & $160(150-170)$ & $0.001^{\mathrm{a}}$ \\
\hline $\begin{array}{l}\text { Diastolic blood pressure, } \\
\mathrm{mmHg} \text {, median (IQR) }\end{array}$ & $90(90-100)$ & $100(90-100)$ & $87.5(83.75-102.5)$ & $90(90-100)$ & 0.087 \\
\hline Abnormal relaxation, $\mathrm{n}(\%)$ & $8(33.33)$ & $35(72.92)$ & $6(75)$ & $38(64.41)$ & $0.009^{\mathrm{a}}$ \\
\hline
\end{tabular}

${ }^{\mathrm{a}} \mathrm{P}<0.01$. IQR, interquartile range.

Associations of RAAS polymorphisms with LV geometry. No statistically significant associations between M235T-AGT, A1166C-R1AngII, G83A-REN, I/D-ACE and A3123CR2AngII polymorphisms and LV geometry were identified.

The M235T-AGT $(\mathrm{P}<0.147)$ and A3123C-R2AngII $(\mathrm{P}<0.156)$ polymorphisms were closest to statistical significance regarding their association with LV geometry. Compared with $M / M$ genotype carriers, the distribution of M235T-AGT genotypes in association with concentric hypertrophy was higher for $T / T, M / T$ genotypes (72.92\%), the distribution in association with eccentric hypertrophy was higher only for $T / T, M / T$ genotypes (100\%), and in association with concentric remodeling was higher for $T / T, M / T$ genotypes $(72.88 \%)$. Regarding the $A 3123 C$-R2AngII gene variant, the distribution of genotypes in the group of hypertensive patients with concentric hypertrophy was higher for $C / C, A / C$ genotype carriers $(43.75 \%)$ (Table V).

Associations of RAAS polymorphisms with RWT. Given the lack of findings between the types of LV geometry and the studied polymorphisms, next, the relationship between the finer aspects of LV geometry with the studied polymorphisms were assessed.

With regard to the $A 3123 C$-R2AngII polymorphism, the $C / C, A / C$ genotypes were statistically significantly associated with RWT $<0.42(\mathrm{P}<0.033)$, and after adjustment for confounders (age, sex, BMI, SBP and DBP), the association remained statistically significant $(\mathrm{P}<0.008)$. Compared with the negative carriers, the chance of a patient exhibiting an RWT value $<0.42$ was $2.72 x$ higher for $C / C, A / C$ genotypes, and 4.02x higher after adjustment for confounders.

No statistically significant associations between M235T-AGT, I/D-ACE, A1166C-R1AngII and G83A-REN with normal or pathological values of RWT were identified, but homozygous and heterozygous carriers had a $>1$-fold increased risk factor for pathological values of RWT in all polymorphisms (Table VI).

Associations of RAAS polymorphisms with pathological LVMI. No statistically significant associations between M235T-AGT, A1166C-R1AngII, G83A-REN, I/D-ACE and A3123C-R2AngII polymorphisms with LVMI were identified; under these conditions; thus, the multivariate analysis was not justified. Compared to the negative carriers, the chance of having pathological LVMI was $1.51 \mathrm{x}$ higher in carriers of the $T / T, M / T$ genotypes (M235T-AGT polymorphism), 1.47x higher in carriers of the $C / C, A / C$ genotypes (A1166C-R1AngII polymorphism), 1.2x higher in carriers of the $G / G-A / G$ genotypes ( $G 83 A-\mathrm{REN}$ polymorphism), and $1.58 x$ higher in carriers of the $D / D, I / D$ genotypes $(I / D$-ACE polymorphism).

The polymorphisms that were closest to being statistically significant regarding their association with LVMI were MM235-AGT $(\mathrm{P}<0.297)$, AA1166-R1AngII $(\mathrm{P}<0.284)$ and I/D-ACE $(\mathrm{P}<0.203)$ (Table VII).

The Hardy-Weinberg equilibrium was present for M235T-AGT, A1166C-R1AngII and G83A-REN polymorphisms, but not the $I / D$-ACE gene variant and $A 3123 C$-R2AngII polymorphism, while eccentric hypertrophy was present in the case of M235T-AGT.

\section{Discussion}

In the medical literature from the last 20 years, data related to cardiac remodeling and LVDD in association with RAAS 
Table III. Characteristics of the patients with essential hypertension with regard to the E/A ratio.

\begin{tabular}{|c|c|c|c|}
\hline \multirow[b]{2}{*}{ Characteristic } & \multicolumn{2}{|c|}{ E/A ratio } & \multirow[b]{2}{*}{ P-value } \\
\hline & $\begin{array}{l}\text { Abnormal relaxation, } \\
n=87\end{array}$ & $\begin{array}{l}\text { Absence of abnormal } \\
\text { relaxation, } n=52\end{array}$ & \\
\hline Age, years, mean (standard deviation) & $61.16(10.21)$ & $52.62(14.13)$ & $0.001^{\mathrm{b}}$ \\
\hline Age $\geq 60$ years, $\mathrm{n}(\%)$ & $54(62.07)$ & $20(38.46)$ & $0.007^{\mathrm{b}}$ \\
\hline \multicolumn{4}{|l|}{ Sex, n $(\%)$} \\
\hline Female & $44(50.57)$ & $27(51.92)$ & 0.878 \\
\hline Male & $43(49.43)$ & $25(48.08)$ & \\
\hline Weight status, n (\%) & & & 0.138 \\
\hline Healthy weight & $8(9.2)$ & $11(21.15)$ & \\
\hline Overweight & $32(36.78)$ & $17(32.69)$ & \\
\hline Obesity & $47(54.02)$ & $24(46.15)$ & \\
\hline Systolic blood pressure, mmHg, median (IQR) & $170(150-180)$ & $160(150-170)$ & 0.38 \\
\hline Diastolic blood pressure, $\mathrm{mmHg}$, median (IQR) & $90(90-100)$ & $90(88.75-100)$ & 0.488 \\
\hline Left ventricular remodeling models, n (\%) & & & $0.009^{\mathrm{b}}$ \\
\hline Normal geometry & $8(9.2)$ & $16(30.77)$ & \\
\hline Concentric hypertrophy & $35(40.23)$ & $13(25)$ & \\
\hline Eccentric hypertrophy & $6(6.9)$ & $2(3.85)$ & \\
\hline Concentric remodeling & $38(43.68)$ & $21(40.38)$ & \\
\hline RWT, median (IQR) & $0.48(0.44-0.53)$ & $0.44(0.4-0.49)$ & $0.001^{\mathrm{b}}$ \\
\hline $\mathrm{RWT}<0.42, \mathrm{n}(\%)$ & $73(83.91)$ & $32(61.54)$ & $0.003^{\mathrm{b}}$ \\
\hline LVM (g), median (IQR) & $206(176-241)$ & $181.5(141.75-234)$ & $0.028^{\mathrm{a}}$ \\
\hline LVMI, g/m², median (IQR) & $100(92-120)$ & $92(72.75-113.75)$ & $0.008^{\mathrm{b}}$ \\
\hline Pathological LVMI, n (\%) & $41(47.13)$ & $15(28.85)$ & $0.033^{\mathrm{a}}$ \\
\hline
\end{tabular}

gene polymorphisms have been inconsistent and contradictory. Discrepancies are explained by interethnic differences, differences in the methodology of recruitment, confounders and associated pathologies (such as DM and CKD).

With regard to the relationship between LVH and sex distribution, Radulescu et al (5) observed a higher prevalence of concentric LVH in men and eccentric LVH in women. In 1999 , Perticone et al (33) reported that male hypertensive patients are at higher risk of developing LVH. Yang et al (7) explained that eccentric LVH is predominantly found in the female sex due to the location of estrogen receptors in cardiac myocytes and fibroblasts. Bahramali et al (2), Sasu et al (8) and Lalande and Johnson (9) all reported that LVDD is more frequently found in women In the present study, there was no statistically significant association between cardiac morphological and functional remodeling and sex distribution, although the frequency of eccentric LVH and LVDD was higher in women, and the frequency of normal cardiac geometry was higher in men.

Cardiac structural and functional changes occur with aging. According to Radulescu (5) and Lin et al (6), hypertensive patients aged over 65 years old had LVH and pathological RWT values According to Bahramali et al (2), the prevalence of LVDD increases in patients aged $>65$ years. In the present study, there was a statistically significant correlation between
LVDD, the three types of cardiac remodeling and the age of hypertensive patients $>60$ years.

Ji et al (34) and Song et al (35) observed that RAAS genetic variants (AGT, ACE, R1 AngII and REN) were significantly associated with high a BP in the Han Chinese population and Korean population Radulescu et al (5) and Du et al (36) showed that high SBP and DBP values influence the type of cardiac remodeling In the present study, only SBP significantly differed between the LV geometry groups, having the highest median value $(170 \mathrm{mmHg})$ in the concentric hypertrophy group, and $160 \mathrm{mmHg}$ in the other three groups. DBP followed a similar pattern, being higher in the concentric hypertrophy group $(100 \mathrm{mmHg})$, and $\sim 90 \mathrm{mmHg}$ in the other three groups, but the differences did not reach the level of significance.

Yang et al (7) showed that SBP and DBP values influence LV diastolic function, and with aging, they contribute to the development of LVDD. In the present study, no statistically significant correlation was found between the mean SBP and DBP values with LVDD.

Obesity influences the pathophysiology of cardiac morphological and functional remodeling in both hypertensive and normotensive patients, as an independent factor or in association with RAAS. According to Woodiwiss and Norton GR (37), 
Table IV. Univariate and multivariate logistic regressions assessing associations between E/A ratio and the genetic variant in a cohort of patients with essential hypertension.

\begin{tabular}{|c|c|c|c|c|c|c|c|c|}
\hline \multirow[b]{2}{*}{ Genetic variants, $\mathrm{n}(\%)$} & \multicolumn{2}{|c|}{$\mathrm{E} / \mathrm{A}$ ratio } & \multirow[b]{2}{*}{$\begin{array}{c}\text { OR } \\
\text { unadjusted }\end{array}$} & \multirow[b]{2}{*}{$95 \% \mathrm{CI}$} & \multirow[b]{2}{*}{ P-value } & \multirow[b]{2}{*}{$\begin{array}{c}\text { OR } \\
\text { adjusted }^{\mathrm{b}}\end{array}$} & \multirow[b]{2}{*}{$95 \% \mathrm{CI}$} & \multirow[b]{2}{*}{ P-value } \\
\hline & $\begin{array}{c}\text { Abnormal } \\
\text { relaxation, } \\
n=87\end{array}$ & $\begin{array}{c}\text { Absence of } \\
\text { abnormal } \\
\text { relaxation, } \\
n=52\end{array}$ & & & & & & \\
\hline$M 235 T$-AGT; $T / T, M / T$ vs. $M / M$ & $68(78.16)$ & $32(61.53)$ & 2.24 & $(1.05-4.8)$ & $0.037^{\mathrm{a}}$ & 2.42 & $(1.05-5.69)$ & $0.039^{\mathrm{a}}$ \\
\hline$A 1166 C$-R1AngII; $C / C, A / C$ vs. $A / A$ & $35(40.22)$ & $13(25)$ & 2.19 & $(1.03-4.89)$ & $0.048^{\mathrm{a}}$ & 1.98 & $(0.88-4.63)$ & 0.105 \\
\hline$G 83 A$-REN; $G / G, A / G$ vs. $A / A$ & $49(56.32)$ & $19(36.53)$ & 2.32 & $(1.14-4.8)$ & $0.021^{\mathrm{a}}$ & 2.39 & $(1.09-5.44)$ & $0.033^{\mathrm{a}}$ \\
\hline$I / D-A C E ; D / D, I / D$ vs. $I / I$ & $32(36.78)$ & $19(36.53)$ & 0.99 & $(0.48-2.01)$ & 0.977 & 1.05 & $(0.47-2.3)$ & 0.911 \\
\hline$A 3123 C$-R2AngII; $C / C, A / C$ vs. $A / A$ & $35(40.22)$ & $16(30.76)$ & 1.62 & $(0.78-3.45)$ & 0.204 & 1.74 & $(0.8-3.88)$ & 0.168 \\
\hline
\end{tabular}

${ }^{\mathrm{a}} \mathrm{P}<0.05$. ${ }^{\mathrm{b}}$ Logistic regression models predicting E/A ratio, in function of each polymorphisms separately, adjusted for age, body mass index, systolic blood pressure and diastolic blood pressure. E/A ratio, ratio of the E wave (the peak velocity blood flow from left ventricular relaxation in early diastole) to the A wave (the peak velocity flow in late diastole caused by atrial contraction); AGT, angiotensinogen; R1AngII, angiotensin II type 1 receptor; R2AngII, angiotensin II type 2 receptor; REN, renin; ACE, angiotensin-converting enzyme; OR, odds ratio; CI, confidence interval.

Table V. Associations between left ventricular geometry and the genetic variant in a cohort of patients with EHT.

\begin{tabular}{lccccr}
\hline & \multicolumn{3}{c}{ Left ventricular geometry } & & \\
\cline { 2 - 3 } Genetic variants, $\mathrm{n}(\%)$ & $\begin{array}{c}\text { Normal } \\
\text { geometry, } \\
\mathrm{n}=24\end{array}$ & $\begin{array}{c}\text { Concentric } \\
\text { hypertrophy, } \\
\mathrm{n}=48\end{array}$ & $\begin{array}{c}\text { Eccentric } \\
\text { hypertrophy, } \\
\mathrm{n}=8\end{array}$ & $\begin{array}{c}\text { Concentric } \\
\text { remodeling, } \\
\mathrm{n}=59\end{array}$ & P-value \\
\hline M235T-AGT; $T / T, M / T$ vs. $M / M$ & $14(58.33)$ & $35(72.92)$ & $8(100)$ & $43(72.88)$ & 0.147 \\
Al166C-R1AngII; $C / C, A / C$ vs. $A / A$ & $5(20.83)$ & $18(37.5)$ & $4(50)$ & $20(34.48)$ & 0.387 \\
$G 83 A$-REN; $G / G, A / G$ vs. $A / A$ & $8(33.33)$ & $24(51.06)$ & $4(50)$ & $30(51.72)$ & 0.471 \\
$I / D$-ACE; $D / D, I / D$ vs. $I / I$ & $11(45.83)$ & $14(29.17)$ & $3(37.5)$ & $23(38.98)$ & 0.538 \\
$A 3123 C$-R2AngII; $C / C, A / C$ vs. $A / A$ & $4(16.67)$ & $21(43.75)$ & $3(37.5)$ & $22(37.93)$ & 0.156 \\
\hline
\end{tabular}

AGT, angiotensinogen; R1AngII, angiotensin II type 1 receptor; REN, renin; R2AngII, angiotensin II type 2 receptor; ACE, angiotensin converting enzyme; EHT, essential hypertension; OR, odds ratio; CI, confidence interval.

obese patients can present with LVH in the absence of high BP values. Rocha et al (38) reported that obese hypertensive patients had LVDD in the absence of LVH. Alpert et al (10) showed that LVDD in obese patients was associated with LVH, and LVDD and eccentric LVH were present in a higher proportion in obese subjects. In the present study, weight status was statistically significantly correlated with LVH, but not with LVDD. Obese and overweight patients had, in a higher proportion, concentric LVH, concentric remodeling and LVDD.

The study by Radulescu et al (5) showed that LVDD is associated with concentric and eccentric LVH, especially if hypertension is of secondary renal cause. Du et al (36) maintained that in hypertensive patients with eccentric hypertrophy, LVDD is present. The results of the present study demonstrated a statistical correlation between cardiac remodeling, the pathological value of LVMI and LVDD. Patients with LVDD had, in an increased proportion of eccentric and concentric hypertrophy, and in a smaller percentage, cardiac remodeling.
Chahal et al (39) reported that the E/A ratio decreases to $<1$ with the increase in the RWT value, and Bamaiyi (40) showed that pathological RWT is statistically significantly associated with LVDD. In the present study, no statistical correlation was found between LVDD and the pathological value of RWT.

In hypertensive Chinese and Uzbek Central Asian subjects, without other associated pathologies, M235T-AGT polymorphisms were associated with LVH according to Tang et al (12) and Kurbanova and Eliseyeva (41) Tran et al (42), Eliseeva et al (43), Jeng (44) and Iwai et al (45) showed that Vietnamese, Uzbek, Chinese and Japanese carriers of the $T / T$ genotype exhibited increased AGT concentrations, which explains the implication of the genetic variant in the development of LVH in patients without other associated diseases. Wang et al (4) demonstrated that the $T / T$ genotype was associated with LVH in Chinese hypertensive patients with CKD in the hemodialysis stage. In contrast, Olcay et al (46) and Shilyakhto et al (47) found no association between LVH and M235T-AGT genetic variants in Turkish and Russian 
Table VI. Univariate and multivariate logistic regressions assessing associations between RWT and the genetic variant in a cohort of patients with essential hypertension.

\begin{tabular}{|c|c|c|c|c|c|c|c|c|}
\hline \multirow[b]{2}{*}{ Genetic variants, n (\%) } & \multicolumn{2}{|c|}{ RWT } & \multirow[b]{2}{*}{$\begin{array}{c}\text { OR } \\
\text { unadjusted }\end{array}$} & \multirow[b]{2}{*}{$95 \% \mathrm{CI}$} & \multirow[b]{2}{*}{ P-value } & \multirow[b]{2}{*}{$\begin{array}{c}\text { OR } \\
\text { adjusted }^{\mathrm{c}}\end{array}$} & \multirow[b]{2}{*}{$95 \% \mathrm{CI}$} & \multirow[b]{2}{*}{ P-value } \\
\hline & $\begin{array}{l}<0.42, \\
\mathrm{n}=105\end{array}$ & $\begin{array}{c}>0.42, \\
n=34\end{array}$ & & & & & & \\
\hline$M 235 T$-AGT; $T / T, M / T$ vs. $M / M$ & $77(73.33)$ & $23(67.64)$ & 1.32 & $(0.55-3)$ & 0.522 & 1.13 & $(0.45-2.71)$ & 0.786 \\
\hline$A 1166 C$-R1AngII; $C / C, A / C$ vs. $A / A$ & $39(37.14)$ & $9(26.47)$ & 1.6 & $(0.7-3.95)$ & 0.285 & 1.56 & $(0.64-4.06)$ & 0.342 \\
\hline$G 83 A-\mathrm{REN} ; G / G, A / G$ vs. $A / A$ & $55(52.38)$ & $13(38.23)$ & 1.71 & $(0.78-3.86)$ & 0.183 & 1.87 & $(0.79-4.57)$ & 0.159 \\
\hline$I / D-\mathrm{ACE} ; D / D, I / D$ vs. $I / I$ & $68(64.76)$ & $20(58.82)$ & 1.29 & $(0.58-2.83)$ & 0.533 & 1.33 & $(0.56-3.12)$ & $0.507^{\mathrm{b}}$ \\
\hline$A 3123 C$-R2AngII; $C / C, A / C$ vs. $A / A$ & $44(41.9)$ & $7(20.58)$ & 2.72 & $(1.13-7.29)$ & $0.033^{\mathrm{a}}$ & 4.02 & $(1.52-12.13)$ & $0.008^{\mathrm{a}}$ \\
\hline
\end{tabular}

${ }^{\mathrm{a}} \mathrm{P}<0.05,{ }^{\mathrm{b}} \mathrm{P}<0.01 .{ }^{\mathrm{c}}$ Logistic regression models predicting E/A ratio, in function of each polymorphisms separately, adjusted for age, body mass index, systolic blood pressure, diastolic blood pressure. RWT, relative wall thickness; AGT, angiotensinogen; R1 AngII, angiotensin II type 1 receptor; R2AngII, angiotensin II type 2 receptor; REN, renin; ACE, angiotensin converting enzyme; OR, odds ratio; CI, confidence interval.

Table VII. Associations between pathological LVMI and the genetic variant in a cohort of patients with essential hypertension.

\begin{tabular}{|c|c|c|c|c|}
\hline \multirow[b]{2}{*}{ Genetic variants, n (\%) } & \multicolumn{2}{|c|}{ LVMI } & \multirow{2}{*}{$\begin{array}{c}\text { Odds ratio }(95 \% \\
\text { confidence interval) }\end{array}$} & \multirow[b]{2}{*}{$\mathrm{P}$-value } \\
\hline & Yes, $n=56$ & No, $n=83$ & & \\
\hline$M 235 T$-AGT; $T / T, M / T$ vs. $M / M$ & $43(76.78)$ & $57(68.67)$ & $1.51(0.69-3.22)$ & 0.297 \\
\hline$A 1166 C$-R1AngII; $C / C, A / C$ vs. $A / A$ & $22(39.28)$ & $26(31.32)$ & $1.47(0.72-3.03)$ & 0.284 \\
\hline$G 83 A-\mathrm{REN} ; G / G, A / G$ vs. $A / A$ & $29(51.78)$ & $39(46.98)$ & $1.20(0.60-2.38)$ & 0.6 \\
\hline$I / D-\mathrm{ACE} ; D / D, I / D$ vs. $I / I$ & $39(69.64)$ & $49(59.03)$ & $1.58(0.77-3.22)$ & 0.203 \\
\hline$C 3123 A$-R2AngII; $C / C, A / C$ vs. $A / A$ & $13(23.21)$ & $21(25.30)$ & $0.93(0.42-2.08)$ & 0.874 \\
\hline
\end{tabular}

AGT, angiotensinogen; R1AngII, angiotensin II type 1 receptor; REN, renin; R2AngII, angiotensin II type 2 receptor; ACE, angiotensin converting enzyme; LVMI, left ventricular mass index.

patients with EHT In the present study, there was a tendency to association, but without statistical significance, between the M235T-AGT genetic polymorphism and cardiac remodeling; carriers of the $T / T, M / T$ genotype have a risk factor for developing LVH compared to carriers of the negative $M / M$ genotype.

Rani et al (22) described the association between the $T / T$ genotype and the increase in RWT value in Indian hypertensive patients. In the present study, there was no statistical association between the M235T-AGT polymorphism and RWT, although the risk of having pathological RWT values increases for hypertensive carriers of $M / T, T / T$ genotypes.

There was a statistically significant association between LVDD and the M235T-AGT polymorphism identified in the present study. However no previous literature confirming or refuting this result could be found.

According to studies conducted by Kurbanova and Eliseyeva (41) and Eliseeva et al (43), the $D$ allele (I/D-ACE) is associated with the severity of the disease, with an unfavorable progression of LVH in Uzbek hypertensive patients. Lynch et al (27) using the data from Hypertension Genetic Epidemiology Network observed that the $I / D$-ACE genetic variant was implicated in the development of LVH amongst white, but not African-American hypertensive participants.
Wang et al (4), Shilyakhto et al (47) and West et al (48) did not identify an association between LVH and the I/D-ACE polymorphism in hypertensive Chinese, Russian and Australian subjects

Bahramali et al (2) and Cosenso-Martin et al (3) showed that the presence of the $D$ allele could be a predictor for the development of LVH in hypertensive patients with LVDD from Iran and Brazil. Smilde et al (13) and Li et al (19) identified the contribution of the $I / D$-ACE genetic variant to the development of LVH in individuals from Netherlands and China, especially if EHT is associated with other diseases, such as CKD In the present study, there was no statistical association between the $I / D$-ACE genotype and cardiac anatomical remodeling; however, patients carrying the $D / D$ and $I / D$ genotypes did exhibit an increased risk of developing LVH.

Studies by Rani et al (22) and Ueno et al (49) reported that the $D$ allele is significantly associated with pathological RWT more frequently in $D / D$ homozygotes than in $I / D$ heterozygotes in Indian and Japanese hypertensive patients. There was no significant correlation between the $I / D$-ACE polymorphism and the pathological RWT value identified in the present study.

Bahramali et al (2) and Rani et al (22) observed that LVDD is associated with the $D$ allele in hypertensive Iranian and Indian patients carrying the; however, no correlation was 
identified between LVDD and the $I / D$-ACE polymorphism in the present study.

Kuznetsova et al (23) and Shilyakhto et al (47) did not identify any association between LVH and A1166C-R1AngII in hypertensive patients from Poland, Russia and Italy. In contrast, Mishra et al (50) reported that Indian patients carrying the $C / C$ and $A / C$ genotypes were at higher risk of LVH and LVDD. In the present study, carriers of the $C / C$ and $A / C$ genotypes had a $n$ increased risk of developing LVH compared to carriers of the $A / A$ genotype, although the difference was not significant.

Lin et al (6) and Smilde et al (13) described in studies conducted in China and Netherlands, respectively, an association between CKD, aged $>60$ years old with the A1166C-R1AngII genetic polymorphism with the risk of development of LVH. In the present study, only patients with EHT were selected, excluding CKD, a potential bias factor related to the primary or secondary nature of hypertension.

In a study by Jin et al (51) amongst patients randomly recruited in a white European population, homozygous patients for the $C / C$ genotype had increased values of LVMI and RWT compared to carriers of the $A$ allele). The results of the present study showed that patients carrying the $C / C$ and $A / C$ genotypes had an increased risk of exhibiting pathological RWT and LVMI values, although the correlation was not significant.

Bahramali et al (2) and $\mathrm{Wu}$ et al (52) showed that the A1166C-R1AngII genetic variant is associated with LVDD in Iranian and Chinese hypertensive patients. Rani et al (22) and Jin et al (51) found a statistical association between this genetic variant and LVH, but not LVDD in Indian and white European populations There was a significant association between LVDD and the $C / C$ and $A / C$ genotypes in the univariate analysis, but in the multivariate analysis this association was not present.

Schmieder et al (53) and Herrmann et al (54) showed that the $A 3123 C$-R2AngII genotype was involved in the pathophysiology of LVH in white male German and British subjects. However, in the present study, there was no statistical significance between this genetic variant and LVH.

From a pathophysiological point of view, Xiao et al (24) reported that electrophysiological stimulation of $\mathrm{R} 2$ AngII improves LV cardiac remodeling and influences cellular hypertrophy in experimental animal models. Schmieder et al (53) showed that white male German hypertensive patients carrying the A allele had pathological values of LVMI and RWT. In the present study, in both univariate and multivariate analysis, it was observed that the $C / C$ and $A / C$ genotypes (A3123C-R2AngII) were associated with non-concentric cardiac remodeling, but not with LVDD. No previous studies have demonstrated this aspect to the best of our knowledge. Thus the present study may be the first to confirm this hypothesis.

West et al (48) found there was no association between the G83A-REN genetic polymorphism in the occurrence of LVH in Australian hypertensive patients. Similarly, in the present study, no statistical correlation between the G83A-REN polymorphism and cardiac anatomy was identified; however, carriers of the $G / G$ and $A / G$ genotypes were at increased risk of LVH and had pathological RWT values. Additionally, in the present study, the $A / A$ genotype and LVDD association was close to the level of statistical significance, and no previous studies assessed this association, to the best of our knowledge.
The limitations of the present study were: i) Characterization of LVDD based on abnormal relaxation alone (without assessing the possible impact of heart rate). It would have been useful to analyze the other components of transmitral flow. Unfortunately, there were no available data for the entire group subjected to genetic analysis. ii) The determined levels of SBP and DBP were influenced, in the case of hypertensive patients on treatment, by the use of the previously recommended medication.

The strengths of the present study are: i) Identification of the preferential distribution of certain RAAS gene variants in the subpopulation with non-concentric remodeling and/or LVDD; and ii) hypertensive patients carrying the M235T-AGT and $G 83 A$-REN genetic variants can develop LVDD when assessing abnormal relaxation, this association emphasizes the significant effect of this genetic polymorphism in the adaptative functional response to EHT. To the best of our knowledge, there are no studies to establish this aspect, making the present study first to determine the association between genetic variants in Romanian patients diagnosed with EHT.

In conclusion, the results confirmed the hypothesis of the adaptive functional association of the variable response to EHT, conditioned by RAAS genetic polymorphisms. The A3123C-R2AngII genetic variant was associated with non-concentric cardiac remodeling as an adaptive response to EHT. Apart from the aforementioned limitations, the present study provides evidence for a differentiated approach for management of hypertensive patients, depending not only on classes of risk, but also on individual vulnerability.

\section{Acknowledgements}

Not applicable.

\section{Funding}

This study was funded by the 'Iuliu Hatieganu' University of Medicine and Pharmacy Cluj-Napoca [grant nos. Doctoral Research Projects (DRP) 7690/26 and DRP 5200/24].

\section{Availability of data and materials}

The datasets used and/or analyzed during the present study are available from the corresponding author on reasonable request.

\section{Authors' contributions}

OM contributed to the conception and design of the study, data collection, data analysis and interpretation, and writing the manuscript. DR contributed to the conception and design of the study and final proofreading. EB contributed to the conception and design of the study, data collection and final proofreading. DCL was involved in data analysis and interpretation. AC contributed to data collection and the critical review of the manuscript. SAB participated in performing the genetic determinations performed a critical review of the manuscript. LMP contributed to the conception and design of the study, data collection, in performing the genetic determinations and gave final approval of the manuscript. All authors read and approved the final manuscript. All authors confirm the authenticity of all the raw data. 


\section{Ethics approval and consent to participate}

Written informed consent was obtained from all participants, prior to their inclusion in the study. The Ethics Committee of the 'Iuliu Hatieganu' University of Medicine and Pharmacy approved the study (approval no. 333/2.06.2015).

\section{Patient consent for publication}

Not applicable.

\section{Competing interests}

The authors declare that they have no competing interests.

\section{References}

1. Williams B, Mancia G, Spiering W, Rosei EA, Azizi M, Burnier M, Clement D, Coca A, Simone GD, et al: 2018 practice guidelines for the management of arterial hypertension of the European society of cardiology and the European society of hypertension ESC/ESH task force for the management of arterial hypertension. J Hypertens 36: 76-88, 2018.

2. Bahramali E, Rajabi M, Jamshidi J, Mousavi SM, Zarghami M, Manafi A and Firouzabadi N: Association of ACE gene D polymorphism with left ventricular hypertrophy in patients with diastolic heart failure: A case-control study. BMJ Open 6: e010282, 2016.

3. Cosenso-Martin LN, Vaz-De-Melo RO, Pereira LR, Cesarino CB Yugar-Toledo JC, Cipullo JP, de Souza Pinhel MA, Souza DR and Vilela-Martin JF: Angiotensin-converting enzyme insertion/deletion polymorphism, 24-h blood pressure profile and left ventricular hypertrophy in hypertensive individuals: A cross-sectional study. Eur J Med Res 20: 74, 2015.

4. Wang AYM, Chung-Ngor Chan J, Wang M, Poon E, Lui SF, Kam-Tao Li P and Sanderson J: Cardiac hypertrophy and remodeling in relation to ACE and angiotensinogen genes genotypes in Chinese dialysis patients. Kidney Int 63: 1899-1907, 2003.

5. Radulescu D, Stoicescu L, Buzdugan E and Donca V: Patterns of left ventricular remodeling among patients with essential and secondary hypertension. Rev Med Chil 141: 1520-1527, 2013.

6. Lin TH, Chiu HC, Lee YT, Su HM, Voon WC, Liu HW, Lai WT and Sheu SH: Association between functional polymorphisms of renin-angiotensin system, left ventricular mass, and geometry over 4 years in a healthy Chinese population aged 60 years and older. J Gerontol A Biol Sci Med Sci 62: 1157-1163, 2007.

7. Yang Y, Zhu LM, Xu JZ, Tang XF and Gao PJ: Comparison of left ventricular structure and function in primary aldosteronism and essential hypertension by echocardiography. Hypertens Res 40: 243-250, 2017.

8. Sasu D, Popescu L and Carauş A: Diastolic dysfunction and heart failure with preserved ejection fraction-general physiopathology and management. Arta Medica 4: 45-48, 2011.

9. Lalande S and Johnson BD: Diastolic dysfunction: A link between hypertension and heart failure. Drugs Today (Barc) 44: 503-513, 2008.

10. Alpert MA, Karthikeyan K, Abdullah O and Ghadban R: Obesity and cardiac remodeling in adults: Mechanisms and clinical implications. Prog Cardiovasc Dis 61: 114-123, 2018.

11. Fountain JH and Lappin SL: Physiology, Renin Angiotensin System. In: StatPearls. StatPearls Publishing, Treasure Island, FL, 2019.

12. Tang W, Devereux RB, Rao DC, Oberman A, Hopkins PN, Kitzman DW and Arnett DK: Associations between angiotensinogen gene variants and left ventricular mass and function in the HyperGEN study. Am Heart J 143: 854-860, 2002.

13. Smilde TDJ, Zuurman MW, Hillege HL, van Veldhuisen DJ, van Gilst WH, van der Steege G, Voors AA, Kors JA, de Jong PE and Navis G: Renal function dependent association of AGTR1 polymorphism (A1166C) and electrocardiographic leftventricular hypertrophy. Am J Hypertens 20: 1097-1103, 2007.

14. Gumprecht J, Domek M, Lip GYH and Shantsila A: Invited review: Hypertension and atrial fibrillation: Epidemiology, pathophysiology, and implications for management. J Hum Hypertens 33: 824-836, 2019.
15. Procopciuc LM, Caracostea G, Zaharie G, Puscas M, Iordache G, Popa M, Colcear D, Olteanu I and Stamatian F: Maternal/newborn genotype contribution of the renin-angiotensin system (Met235Thr, Thr174Met, I/D-ACE, A2350G-ACE, A1166C-AT2R1, C3123A-AT2R2, 83A/G-REN) to the risk of pre-eclampsia: A Romanian study. J Reni Angiotensin Aldosterone Syst 12: 539-548, 2011.

16. Alves GB, Oliveira EM, Alves CR, Rached HRS, Mota GFA, Pereira AC, Rondon MU, Hashimoto NY, Azevedo LF, Krieger JE and Negrão CE: Influence of angiotensinogen and angiotensin-converting enzyme polymorphisms on cardiac hypertrophy and improvement on maximal aerobic capacity caused by exercise training. Eur J Cardiovasc Prev Rehabil 16: 487-492, 2009.

17. Bahramali E, Firouzabadi N, Rajabi M, Manafi A, Zarghami M, Mousavi SM and Jamshidi J: Association of renin-angiotensin-aldosterone system gene polymorphisms with left ventricular hypertrophy in patients with heart failure with preserved ejection fraction: A case-control study. Clin Exp Hypertens 39: 371-376, 2017.

18. Li S, Wang Z, Yang X, Hu B, Huang Y and Fan S: Association between circulating angiotensin-converting enzyme 2 and cardiac remodeling in hypertensive patients. Peptides 90: 63-68, 2017.

19. Li X, Li Y, Jia N, Guo S, Chu S and Niu W: Angiotensin-converting enzyme gene deletion allele increases the risk of left ventricular hypertrophy: Evidence from a meta-analysis. Mol Biol Rep 39: 10063-10075, 2012.

20. Arumugam S, Sreedhar R, Thandavarayan RA, Karuppagounder V, Krishnamurthy P, Suzuki K, Nakamura M and Watanabe K: Angiotensin receptor blockers: Focus on cardiac and renal injury. Trends Cardiovasc Med 26: 221-228, 2016.

21. Jaźwiec P, Gać P, Chaszczewska-Markowska M, Bogunia-Kubik K, Mazur G and Poręba R: Genetically determined enlargement of carotid body evaluated using computed angiotomography. Respir Physiol Neurobiol 254: 10-15, 2018

22. Rani B, Kumar A, Bahl A, Sharma R, Prasad R and Khullar M: Renin-angiotensin system gene polymorphisms as potential modifiers of hypertrophic and dilated cardiomyopathy phenotypes. Mol Cell Biochem 427: 1-11, 2017.

23. Kuznetsova T, Staessen JA, Thijs L, Kunath C, Olszanecka A, Ryabikov A, Tikhonoff V, Stolarz K, Bianchi G, Casiglia E, et al: Left ventricular mass in relation to genetic variation in angiotensin II receptors, renin system genes, and sodium excretion. Circulation 110: 2644-2650, 2004.

24. Xiao Y, Long WQ, Guan KP, Long M, Lu GH and Huang ZB: Role of angiotensin II type 2 receptor during electrophysiological remodeling of left ventricular hypertrophic myocardium in spontaneously hypertensive rats. J Am Soc Hypertens 12: 58-65, 2018.

25. Vamsi UM, Swapna N, Usha G, Vishnupriya S and Padma T: Contribution of REN gene MBbo I polymorphism in conferring risk for essential hypertension: A case control study from South India. J Renin Angiotensin Aldosterone Syst 14: 242-247, 2013.

26. Sun B, Williams JS, Pojoga L, Chamarthi B, Lasky-Su J, Raby BA, Hopkins PN, Jeunemaitre X, Brown NJ, Ferri C and Williams GH: Renin gene polymorphism: Its relationship to hypertension, renin levels and vascular responses. J Renin Angiotensin Aldosterone Syst 12: 564-571, 2011.

27. Lynch AI, Tang W, Shi G, Devereux RB, Eckfeldt JH and Arnett DK: Epistatic effects of ACE I/D and AGT gene variants on left ventricular mass in hypertensive patients: The HyperGEN study. J Hum Hypertens 26: 133-140, 2012.

28. Borai IH, Hassan NS, Shaker OG, Ashour E, Badrawy MEl, Fawzi OM and Mageed L: Synergistic effect of ACE and AGT genes in coronary artery disease. Beni Suef University J Basic Appl Sci 7: 111-117, 2018

29. e-Echocardiography: Ejection Fraction. JLS Interactive, LLC, Lincoln, NE, 2020. https://e-echocardiography.com/page/page. php?UID=175615301. Accessed February 1, 2020.

30. Wigginton JE, Cutler DJ and Abecasis GR: A note on exact tests of Hardy-Weinberg equilibrium. Am J Hum Genet 76: 887-893, 2017.

31. R Core Team: R: A language and environment for statistical computing. R foundation for Statistical Computing, Vienna, 2019. http://www.R-project.org/

32. González JR, Armengol L, Solé X, Guino E, Mercader JM, Estivill X and Moreno V: SNPassoc: SNPassoc: an R package to perform whole genome association studies. Bioinformatics 23: 654-655, 2007 
33. Perticone F, Maio R, Cosco C, Ceravolo R, Iacopino S, Chello M, Mastroroberto P, Tramontano D and Mattioli PL: Hypertensive left ventricular remodeling and ACE-gene polymorphism. Cardiovasc Res 43: 192-199, 1999.

34. Ji L, Cai X, Zhang L, Fei L, Wang L, Su J, Lazar L, Xu J and Zhang Y: Association between polymorphisms in the reninangiotensin-aldosterone system genes and essential hypertension in the Han Chinese population. PLoS One 28: e72701, 2013.

35. Song SB, Jin HS, Hong KW, Lim JE, Moon JY, Jeong KH, Ihm CG, Lee TW, Oh B and Lee SH: Association between renin-angiotensin-aldosterone system-related genes and blood pressure in a Korean population. Blood Press 20: 204-210, 2011.

36. Du GQ, Li HR, Xue JY, Chen S, Du P, Wu Y and Tian JW: Wave intensity analysis can identify eccentric cardiac hypertrophy in hypertensive patients with varied left ventricular configurations. J Ultrasound Med 34: 2019-2027, 2015.

37. Woodiwiss AJ and Norton GR: Obesity and left ventricular hypertrophy: The hypertension connection. Curr Hypertens Rep 17: 539, 2015.

38. Rocha IEGM, Victor EG, Braga MC, Silva OB and de Moraes Chaves Becker M: Echocardiography evaluations for asymptomatic patients with severe obesity. Arq Bras Cardiol 88 52-58, 2007 (In English, Portuguese).

39. Chahal NS, Lim TK, Jain P, Chambers JC, Kooner JS and Senior R: New insights into the relationship of left ventricular geometry and left ventricular mass with cardiac function: A population study of hypertensive subjects. Eur Heart J 31: 588-594, 2010.

40. Bamaiyi AJ, Norton GR, Peterson V, Libhaber CD, Sareli P and Woodiwiss AJ: Limited contribution of left ventricular mass and remodelling to the impact of blood pressure on diastolic function in a community sample. J Hypertens 37: 1191-1199, 2019.

41. Kurbanova D and Eliseyeva M: Genetic background of left ventricular hypertrophy in Uzbek hypertensive men. Turk Kardiyol Dern Ars 38: 466-472, 2010.

42. Tran T, Mai TP, Tran HCB, Le LHG, Vu HA, Tran TK, Hoang SV, Chau HN and Do MD: Association between AGT M235T and left ventricular mass in vietnamese patients diagnosed with essential hypertension. Front Cardiovasc Med 8: 608948, 2021.

43. Eliseeva MR, Srozhidinova NZ, Khamidullaeva GA and Abdullaeva GZh: Genetic determinants of cardiovascular remodeling in uzbek patients with essential hypertension. Ter Arkh 81: 64-69, 2009, 2017 (In Russian).

44. Jeng JR: Left ventricular mass, carotid wall thickness, and angiotensinogen gene polymorphism in patients with hypertension. Am J Hypertens 12: 443-450, 1999.
45. Iwai N, Shimoike H, Ohmichi $\mathrm{N}$ and Kinoshita $\mathrm{M}$ : Angiotensinogen gene and blood pressure in the japanese population. Hypertension 25 (4 Pt 2): 688-693, 1995.

46. Olcay A, Nişanci Y, Ekmekçi CG, Ozbek U, Sezer M, Umman B and Buğra Z: Angiotensinogen M235T polymorphism and left ventricular indices in treated hypertensive patients with normal coronary arteries. Anadolu Kardiyol Derg 7: 257-261, 2007.

47. Shilyakhto EV, Shwartz EI, Nefedova YB, Zukova AV, Vinnic TA and Conrady AO: Lack of association of the renin-angiotensin system genes polymorphisms and left ventricular hypertrophy in hypertension. Blood Press 10: 135-141, 2001.

48. West MJ, Summers KM, Burstow DJ, Wong KK and Huggard PR: Renin and angiotensin-converting enzyme genotypes in patients with essential hypertension and left ventricular hypertrophy. Clin Exp Pharmacol Physiol 21: 207-210, 1994.

49. Ueno $\mathrm{H}$, Takata $\mathrm{M}$, Yasumoto $\mathrm{K}$, Tomita $\mathrm{S}$ and Inoue $\mathrm{H}$ Angiotensin-converting enzyme gene polymorphism and geometric patterns of hypertensive left ventricular hypertrophy. Jpn Heart J 40: 589-98, 1999.

50. Mishra A, Srivastava A, Kumar S, Mittal T, Garg N, Agarwal SK, Pande S and Mittal B: Role of angiotensin II type 1 (AT1 A1166C) receptor polymorphism in susceptibility of left ventricular dysfunction. Indian Heart J 67: 214-221, 2015.

51. Jin Y, Kuznetsova T, Thijs L, Schmitz B, Liu Y, Asayama K, Brand SM, Heymans S, Brand E, Fagard R and Staessen JA: Association of left ventricular mass with the AGTR1 A1166C polymorphism. Am J Hypertens 25: 472-478, 2012.

52. Wu CK, Tsai CT, Chang YC, Luo JL, Wang YC, Hwang JJ, Lin JL, Tseng CD and Chiang FT: Genetic Polymorphism of the angiotensin II type 1 receptor gene and diastolic heart failure. J Hypertens 27: 502-507, 2009.

53. Schmieder RE, Erdmann J, Delles C, Jacobi J, Fleck E, Hilgers $\mathrm{K}$ and Regitz-Zagrosek V: Effect of the angiotensin II type 2-receptor gene $(+1675 \mathrm{G} / \mathrm{A})$ on left ventricular structure in humans. J Am Coll Cardiol 37: 175-182, 2001.

54. Herrmann SM, Nicaud V, Schmidt-Petersen K, Pfeifer J, Erdmann J, McDonagh T, Dargie HJ, Paul $M$ and Regitz-Zagrosek V: Angiotensin II type 2 receptor gene polymorphism and cardiovascular phenotypes: the GLAECO and GLAOLD studies. Eur J Heart Fail 4: 707-712, 2002.

(c) (i) () This work is licensed under a Creative Commons Attribution-NonCommercial-NoDerivatives 4.0 International (CC BY-NC-ND 4.0) License. 